\title{
Female dispersal patterns influenced by male tenure duration and group size in western lowland gorillas
}

\author{
Marie L. Manguette ${ }^{1,2}$ (1) Andrew M. Robbins ${ }^{1} \cdot$ Thomas Breuer $^{2,3} \cdot$ Emma J. Stokes $^{4} \cdot$ Richard J. Parnell $^{4}$. \\ Martha M. Robbins ${ }^{1}$
}

Received: 24 January 2020 / Revised: 27 May 2020 / Accepted: 29 May 2020 / Published online: 11 June 2020

(C) The Author(s) 2020

\begin{abstract}
Evaluating the factors influencing the patterns of female dispersal in mammals is critical to understanding its importance for male and female reproductive strategies and the evolution of social systems. In western lowland gorillas, females emigrate from their natal group (natal dispersal) but also disperse between groups multiple times in their life (secondary dispersal). This strategy is uncommon in primates and may reflect females seeking to reduce feeding competition or female choice for males that can provide protection against infanticide. In this study, we test how inbreeding avoidance, group size, and male competitive ability could influence female dispersal in western gorillas, using 25 natal and 285 secondary dispersal events collected over 20 years at Mbeli Bai. We found that while all females dispersed out of their natal group, presumably to avoid inbreeding, females also left their group before having their first offspring when the dominant male was not their father, pointing towards unconditional dispersal by nulliparous females. Regarding secondary dispersal, we found that females were more likely to stay with males that were at the beginning of their tenure than transfer and more likely to disperse away from (presumably old) males that were near the end of their tenure or closer to their death. Females were also more likely to leave larger groups for smaller ones suggesting a potential effect of within-group feeding competition or avoidance of outsider males or predators. This study highlights the intersexual conflict found in gorillas: while female choice for high-quality males may influence the formation of their relatively rare social system, smaller group size may be more important for females than previously thought, which runs counter to the males' interest of having a high number of females.
\end{abstract}

\section{Significance}

Dispersal is a very important life strategy for most group-living mammals. Secondary dispersal by females is a rare behavior but is believed to be a counterstrategy against sexual coercion by males, reduces feeding competition, assists in predator avoidance, and facilitates mate choice. We studied the factors influencing secondary dispersal in western lowland gorillas. We found that the duration of male tenure and the size of the group influences female transfer decisions. This study shows that female reproductive strategies such as secondary dispersal may be very powerful to counter the risk of infanticide through female choice for better protector males but also to reduce the impact of feeding competition or to avoid predators or outsider males.

Keywords Gorilla gorilla $\cdot$ Female secondary dispersal $\cdot$ Natal dispersal $\cdot$ Male competitive ability $\cdot$ Infanticide risk $\cdot$ Feeding competition · Female mate choice

Communicated by M. A van Noordwijk

Electronic supplementary material The online version of this article (https://doi.org/10.1007/s00265-020-02863-8) contains supplementary material, which is available to authorized users.

Marie L. Manguette

marie_manguette@eva.mpg.de

Extended author information available on the last page of the article

\section{Introduction}

Dispersal has profound consequences for gene flow, the evolution of social group patterns, and the geographic distributions of animals (Clobert et al. 2012). Dispersal is usually male-biased in mammals; however, female dispersal also occurs regularly (Strier 1994) and is expected to occur when the benefits of moving to outweigh the costs (Clobert et al. 2012). In social species, the potential benefits of female dispersal 
include inbreeding avoidance, reduction of feeding competition, reduction of predation and infanticide risk, reduction of mate competition, mate choice, disease avoidance, and increase genetic diversity (Amos et al. 2001; Lukas and Clutton-Brock 2011) (Table 1). The potential costs of female dispersal include aggression towards immigrants (Isbell and Van Vuren 1996), loss of habitat familiarity (Bonte et al. 2012), loss of opportunity to help and be helped by kin (Young et al. 2005), or reproductive costs such as longer intervals between births (Debeffe et al. 2015; Walker et al. 2018; Manguette et al. 2019). To determine if and when to transfer, a female may gather information on other social groups and evaluate the costs and benefits of such a decision (Isbell and Van Vuren 1996; Clobert et al. 2009).

Females may disperse from their natal groups to avoid inbreeding, especially if their father may still be in the group (Ims and Hjermann 2001; Clutton-Brock and Lukas 2012). If females are not able to recognize kin, a fixed strategy (unconditional dispersal) allowing females to transfer before the first parturition regardless of whether a male relative is present, may evolve to avoid inbreeding (Bowler and Benton 2005). Following natal dispersal, any subsequent "secondary" dispersal is often attributed to socioecological factors (Isbell and Van Vuren 1996; Clutton-Brock and Lukas 2012). Female secondary dispersal refers to a transfer between breeding groups and is known to occur in very few species (tropical bats: Nagy et al. 2007, feral horses: Debeffe et al. 2015, Thomas langurs: Sterck and Korstjens 2000, and gorillas: Robbins and Robbins 2015). Females may leave larger groups and join smaller groups to avoid feeding competition and intrasexual competition within groups, or reduced attraction by outsider males or predators (Hill and Lee 1998; CluttonBrock and Lukas 2012). Conversely, larger groups may provide better protection against predators due to increased

Table 1 Summary of hypotheses and variables used

\begin{tabular}{|c|c|c|}
\hline Predictions & Variables & Hypotheses \\
\hline Inbreeding avoidance $^{\mathrm{a}}$ & $\begin{array}{l}\text { Silverback of the group is } \\
\text { the father (YES/NO) }\end{array}$ & $\begin{array}{l}\text { Females have conditional dispersal: they transfer from } \\
\text { natal group to avoid inbreeding when their fathers are } \\
\text { present in the group } \\
\text { Females have unconditional dispersal: Females transfer } \\
\text { upon reaching maturity regardless of relatedness with } \\
\text { the silverback in the group }\end{array}$ \\
\hline $\begin{array}{l}\text { Within-group feeding competition/reduced } \\
\text { attraction by extra-group males or predators }\end{array}$ & $\begin{array}{l}\text { Group size (number of weaned } \\
\text { individuals) }\end{array}$ & $\begin{array}{l}\text { (1) Emigration rate increases with increasing group size } \\
\text { (2) Immigration rate decreases with increasing group size } \\
\text { (3) Destination group is smaller than group of origin }\end{array}$ \\
\hline $\begin{array}{l}\text { Between-group feeding competition/predation } \\
\text { avoidance due to increased detection }\end{array}$ & $\begin{array}{l}\text { Group size (number of } \\
\text { weaned individuals) }\end{array}$ & $\begin{array}{l}\text { (1) Emigration rate decreases with increasing group size } \\
\text { (2) Immigration rate increases with increasing group size } \\
\text { (3) Destination group is larger than group of origin }\end{array}$ \\
\hline Infanticide risk/predation avoidance & Elapsed tenure $^{\mathrm{b}}$ & $\begin{array}{l}\text { (1) Emigration rate increases with increasing elapsed } \\
\text { tenure } \\
\text { (2) Immigration rate decreases with increasing elapsed } \\
\text { tenure } \\
\text { (3) Males in the destination groups are earlier in their } \\
\text { tenure than males in group of origin }\end{array}$ \\
\hline Infanticide risk/predation avoidance & Remaining tenure $^{\mathrm{c}}$ & $\begin{array}{l}\text { (1) Emigration rate increases with decreasing } \\
\text { remaining tenure } \\
\text { (2) Immigration rate decreases with decreasing } \\
\text { remaining tenure } \\
\text { (3) Males in the destination groups are further away from } \\
\text { the end of their tenure than males in group of origin }\end{array}$ \\
\hline Infanticide risk/male experience & $\begin{array}{l}\text { Unit type (solitary male } \\
\text { or breeding group) }\end{array}$ & $\begin{array}{l}\text { Immigration rate is higher in breeding groups compared } \\
\text { with solitary males }\end{array}$ \\
\hline Infanticide risk/predation avoidance & $\begin{array}{l}\text { Infant mortality prior to transfer } \\
\text { (yes/no) }\end{array}$ & $\begin{array}{l}\text { Emigration rate increases after the } \\
\text { death of an offspring }\end{array}$ \\
\hline
\end{tabular}

${ }^{a}$ For testing inbreeding avoidance, we used only the natal transfers or subsequent transfers by nulliparous females; every other hypothesis uses the voluntary secondary transfers

${ }^{\mathrm{b}}$ The beginning of the tenure is known. Used as a proxy for male competitive ability

${ }^{\mathrm{c}}$ The end of the tenure is known. Used as a proxy for male competitive ability. We also tested the time until the silverback died (in SI3) 
detection rates, and they may have an advantage in betweengroup feeding competition, especially in species with clumped-food resources (van Schaik 1989). In polygynous species, females may transfer to a male that provides better protection against infanticide or predation. If young solitary males are not yet strong enough to provide such protection, then females may be more likely to join an established group (Clutton-Brock and McAuliffe 2009). Length of male dominance tenure is expected to reflect variation in male strength and male-male contest competition, with males predicted to be more vulnerable to competitors when they have passed their prime (Steenbeek 2000; Alberts 2012). Male competitive ability is therefore expected to decline as their tenure duration increases, so it could be advantageous for females to join males early in their tenures (Steenbeek 2000; Sterck et al. 2005; Alberts 2012).

Western gorillas are an interesting species to study female dispersal because both natal and secondary transfers are common (Robbins and Robbins 2015, 2018). Female western lowland gorillas (Gorilla gorilla gorilla) live almost exclusively in one-male groups consisting of only one silverback (fully mature adult male), adult females, and immature individuals (Parnell 2002; Gatti et al. 2004; Robbins and Robbins 2018). Breeding groups begin when females transfer to a bachelor group or a lone silverback (Robbins and Robbins 2018). The silverback's tenure ends when all females leave (and the group becomes either non-reproductive or the male becomes solitary) or when he dies and the group consequently disintegrates. The death of the silverback leads to "involuntary" female transfers to join an extra-group male, who is likely to kill their unweaned offspring (Watts 1989; Robbins and Robbins 2018). Transfers are considered "voluntary" when females switch groups during intergroup encounters while the current silverback is alive (Stokes et al. 2003). Voluntary dispersal generally does not occur when females have dependent offspring because these would be vulnerable to infanticide (Robbins and Robbins 2015). Therefore, during each 5-year interbirth interval, females have only a few months to transfer between weaning an infant and conceiving again (Sterck et al. 2005; Robbins and Robbins 2015; Sicotte et al. 2017).

Inbreeding avoidance has been considered a probable cause of natal dispersal in western gorillas, but due to group disintegrations, not all nulliparous females reach maturity in a group with their putative father (i.e., the same silverback who was dominant when the female was born). In previous studies, it was not yet clear whether natal dispersal is more likely when female western gorillas are still with their putative father or other close male relatives. Secondary dispersal by female western gorillas has typically been attributed to a potential reduction of feeding competition, disease avoidance, or increased protection against predation (e.g., leopards) and infanticidal males due to better male competitive abilities in the new group (Harcourt and Stewart 2007; Baudouin et al. 2019).
Studies of feeding competition have shown little or no influence of group size upon female fertility (Robbins et al. 2007; Manguette et al. 2019). Yet, if females leave groups as soon as feeding competition begins to intensify, dispersal may be a more sensitive measure of within-group competition than studies of female fertility (Watts 1990; Robbins et al. 2007). Infant survival was higher in larger western gorilla groups, which may arise from increased detection of predators, or because females aggregate around males who provide better protection (Breuer et al. 2010). Females may therefore prefer a group of intermediate size to account for the potentially conflicting influences of within-group competition versus protection. Stokes et al. (2003) found that female western lowland gorilla transferred preferentially to smaller groups, but Harcourt and Stewart (2007) suggested that the distribution of those transfers would be expected if females transferred randomly with respect to group size. Therefore, the potential influence of group size upon female dispersal remains to be determined.

In western gorillas, infant mortality was significantly higher during the last 5 years of the male tenure than earlier in the tenure, suggesting that those males became less capable of providing protection against predators or infanticidal males (Manguette et al. 2019). At Mbeli, the infanticide rate after group disintegration is around 12\% (Breuer et al. 2010; Robbins et al. 2013). Given the high costs of infanticide after the silverback's death, females should leave a silverback if they perceive he is weak and may not survive long enough for them to wean a new infant (Manguette et al. 2019). Females may also use group composition to assess the competitive ability of the male using criteria described in Parnell 2002 (e.g., younger groups may have fewer juveniles and subadults). Using such criteria, Baudouin et al. 2019 found that females appear to leave older groups for younger groups, but changes in female transfer patterns throughout the male dominance tenure have not been directly examined (Robbins and Robbins 2015).

To investigate the factors influencing dispersal decisions, we examined natal and secondary female dispersal patterns in a healthy population of western lowland gorillas (Gorilla gorilla gorilla) from over two decades (1995-2015) of continuous observations at Mbeli Bai in northern Republic of Congo. First, we quantify the occurrence of dispersal by nulliparous females when they were or were not with their putative father, cases of involuntary transfer, and voluntary secondary transfer. We then tested the effects of socio-ecological factors on secondary transfer probability (using only voluntary transfers as they reflect female choice) using three complementary variables: emigration rates, immigration rates, and differences between the group of origin and the group of destination (Table 1). We first tested whether dispersing females preferred smaller groups (to avoid within-group feeding competition or reduced attraction by extra-group males or predators) or larger 
disappearance (Breuer et al. 2010). In the case of breeding groups, silverback death resulted in group disintegration.

\section{Natal dispersal}

Voluntary natal dispersal rates were calculated by dividing the number of voluntary natal dispersal cases by the total number of natal dispersal events. Involuntary natal dispersal rates were calculated by dividing the number of involuntary natal dispersal cases (when females in their natal group dispersed following the death of their putative father) by the total number of natal dispersal events. We used $t$ tests to determine whether the type of natal dispersal (voluntary vs involuntary) had an effect on the female's choice of group (group size). Similar tests for the variables estimating tenure duration were not possible due to sample size.

\section{Variables for the potential influences upon secondary dispersal}

To examine if feeding competition and/or predation avoidance influenced female secondary dispersal patterns, we used the size of the group (number of weaned individuals) at the time of transfer. The number of weaned individuals in a group was highly correlated with the number of adult females in the group ( $R=0.78, N=300, p<0.001)$, and we therefore only used the weaned individual group size. We used a quadratic term to test for the possibility of a non-linear relationship of group size due to a combination of within- and between-group feeding competition and/or predation pressure (Markham et al. 2015; Grueter et al. 2018).

Our measures of male competitive ability were based on the tenure duration, which we calculated as the interval between the first and last dates that a silverback was observed in association with adult females. The end of a tenure was when the silverback disappeared or when all females left him. We observed only five full tenures so our analyses were based on two partial perspectives: the elapsed tenure (the duration since the tenure began) and the remaining tenure (the time until the tenure ended) (Fig. 1). Two silverbacks had an intermediate period in their tenure without any adult females and the groups were considered non-breeding groups (51 months and 13 months), and those periods were subtracted from the tenure duration. We considered male tenure duration as a better proxy than male age for competitive ability because it is likely to vary among males of the same age and because the birthdates of the males were typically unknown. Furthermore, the estimated age of the silverback was significantly correlated with the tenure duration (elapsed tenure: $R=0.92, N=214, p<0.001$, remaining tenure: $R=-0.39, N=127, p<0.001)$. As an additional measure for male competitive ability, we used the time until the silverback died (see supplementary material S3). Lastly, we tested whether females were more likely to leave after the death of an offspring. Females may use the death of their offspring to assess the competitive ability of the male and decide whether to leave him.

\section{Data analysis}

We used three different variables to test factors influencing secondary dispersal: emigration rate (when a female left the group), immigration rate (when a female appeared in the group), groups of origin and destination (when the group that the female left and the group that she joined were both known).

\section{Emigration rate}

The "emigration rate" is defined as the number of transfers divided by the number of decisions (transfers plus births). We ran generalized linear mixed models (GLMM, Baayen 2008) with a binomial error structure and logit link function to evaluate the potential influences upon secondary female transfers. The dependent variable equaled " 1 " whenever a female made a voluntary secondary transfer and it equaled " 0 " whenever she gave birth (Robbins et al. 2009c). Thus, we compared the probability of transferring versus staying in the current group to reproduce. We used two datasets; in the first, we included all secondary transfers including cases where females disappeared and in the second, we limited the analyses to transfers
Fig. 1 Graphical description of tenure duration. Elapsed tenure is the duration since the first female joined the silverback. The remaining tenure is the time until the silverback dies or when his last female transfers out of the group (from Manguette et al. 2019 , reproduced with permission of the lead author)

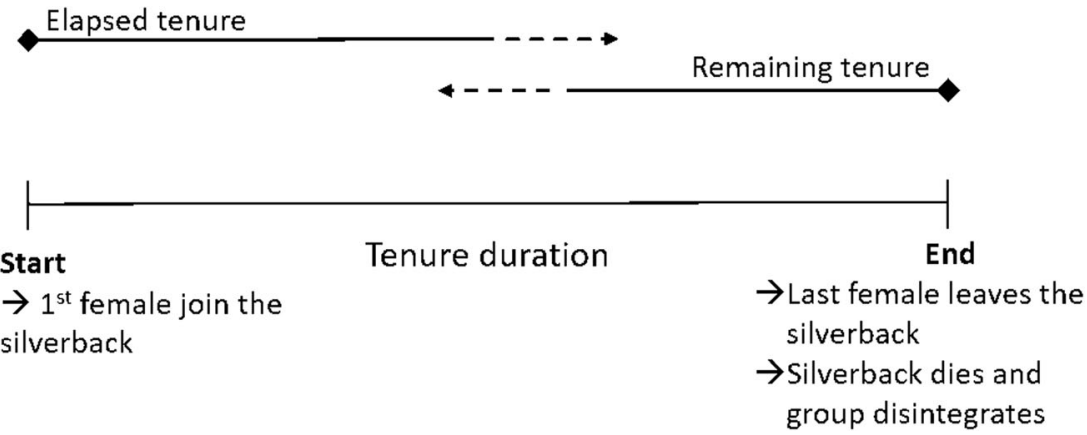


between known groups. The results of the second set of models are presented in supplementary material S2. Due to different datasets available for each variable and to avoid collinearity, we tested each of the potential influences as a predictor variable (group size, elapsed tenure, remaining tenure, and survival of the previous offspring to age four) in a separate model (Table 3). We controlled for the age of the female as well as a quadratic effect of female age in all models (e.g., younger females may transfer more frequently than middleaged females due to longer time window before the first conception, and older females may transfer more frequently due to lower reproductive success, see Fig. S1). We included the identity of the female and the identity of the group as random effects as well as all associated random slopes because the individual females may transfer multiple times and females may transfer from the same group. We compared the full models with respective null models lacking the predictor variables but comprising the same random effects structure as the full model (Forstmeier and Schielzeth 2011) using a likelihood ratio test (Dobson and Barnett 2008). We assessed model stability by comparing the estimates obtained from a model based on all data with those obtained from models with each level of the random effects excluded one at a time. To rule out collinearity, we determined the variance inflation factor (Field 2005) for a standard linear model excluding the random effects. All models were implemented in version 3.5.1 of R ( R Core Team 2017) using the function "glmer" of the package lme4.

\section{Immigration rate}

Group size and tenure duration We ran a linear regression to examine the relationship between group size and immigration rates. The model contained one data point for each group size that was observed (starting at size two, excluding solitary males). The response variable was the immigration rate, which was calculated as the number of immigrations divided by the number of years that each group size was observed. The predictor variable was group size. To avoid excessive influence from group sizes with scant data, each data point was weighted according to the number of years that the group size was observed. We ran similar linear regression models to examine immigration rates versus elapsed tenure and remaining tenure.

Table 3 Emigration rates. Summary of mixed models used for the analyses of female voluntary transfer and comparison with their respective null model. The models used a full dataset in which we

included the known transfers and the individuals that disappeared. $p$ values considered significant $(p<0.05)$ are in bold and trends $(p<0.07)$ are in italics

\begin{tabular}{|c|c|c|c|c|c|c|c|c|c|}
\hline Model & Effects addressed & $\begin{array}{l}\text { Response } \\
\text { variable }\end{array}$ & Test predictors & $\begin{array}{l}\text { Control } \\
\text { predictors }\end{array}$ & $\begin{array}{l}\text { Random effects }(N) \text { (random } \\
\text { slopes) }\end{array}$ & $\begin{array}{l}\text { Sample } \\
\text { size }\end{array}$ & Chi-sq & $\mathrm{df}$ & $p$ \\
\hline $1^{\mathrm{a}}$ & $\begin{array}{l}\text { Feeding } \\
\text { competition/predator } \\
\text { avoidance }\end{array}$ & $\begin{array}{l}\text { Emigration } \\
\text { rate }\end{array}$ & Group size ${ }^{(2)}$ & Female age ${ }^{(2)}$ & $\begin{array}{l}\text { Group ID }(N=41) \text { (group } \\
\left.\text { size }^{(2)}, \text { female age }{ }^{(2)}\right) \\
\text { Female ID }(N=132)\left(\text { group }^{(2)}, \text { female age }{ }^{(2)}\right) \\
\text { size }^{(2)}\end{array}$ & 365 & 7.513 & 2 & 0.023 \\
\hline 2 & $\begin{array}{l}\text { Male competitive ability } \\
\text { and experience }\end{array}$ & $\begin{array}{l}\text { Emigration } \\
\text { rate }\end{array}$ & Elapsed tenure & Group size ${ }^{(2)}$ & $\begin{array}{l}\text { Group ID }(N=24) \\
\quad(\text { elapsed tenure, group } \\
\left.\text { size }^{(2)}, \text { female age }{ }^{(2)}\right) \\
\text { Female ID }(N=106) \\
\quad(\text { elapsed tenure, group } \\
\left.\text { size }^{(2)}, \text { female age } e^{(2)}\right)\end{array}$ & 257 & 10.996 & 1 & $<0.001$ \\
\hline $3^{\mathrm{b}}$ & $\begin{array}{l}\text { Male competitive ability } \\
\text { and experience }\end{array}$ & $\begin{array}{l}\text { Emigration } \\
\text { rate }\end{array}$ & Remaining tenure & $\begin{array}{l}\text { Female age }^{(2)} \\
\text { Group size }^{(2)}\end{array}$ & $\begin{array}{l}\text { Group ID }(N=21) \\
\left.\quad \text { remaining tenure, group }^{(2)}, \text { female age }{ }^{(2)}\right) \\
\text { size }^{(2)} \\
\text { Female ID }(N=78) \\
\quad\left(\text { remaining tenure, group }^{(2)}, \text { female age }{ }^{(2)}\right) \\
\text { size }^{(2)}\end{array}$ & 167 & 14.473 & 1 & $<0.001$ \\
\hline 4 & $\begin{array}{l}\text { Male competitive ability } \\
\text { and experience }\end{array}$ & $\begin{array}{l}\text { Emigration } \\
\text { rate }\end{array}$ & $\begin{array}{l}\text { Survival of } \\
\text { previous } \\
\text { offspring to } \\
\text { age four }^{\mathrm{c}}\end{array}$ & - & $\begin{array}{l}\text { Group ID }(N=24) \\
\text { Mother ID }(N=56)\end{array}$ & 113 & 3.338 & 1 & 0.068 \\
\hline
\end{tabular}

\footnotetext{
${ }^{\text {a }}$ A similar model using a smaller but more precise dataset with only transfers to known groups revealed insignificant results for the variable Group size (See SI2)

${ }^{(2)}$ Indicate that a square term was also used

${ }^{\mathrm{b}}$ Remaining tenure: the model including female age and group size is over parameterized and unstable, a univariate analysis testing only the remaining tenure revealed similar results

${ }^{\mathrm{c}}$ This model included only transfers that resulted in conceiving an infant and can therefore not include any missing individuals
} 
Social unit type We performed rate-based $\chi^{2}$ calculations to compare the rates of female immigration into groups versus solitary males. We tallied the number of immigrations into groups versus solitary males, and the number of years that each type of social unit was observed (unit-years). We calculated the expected number of immigrations into each type of social unit, based on the null hypothesis that the observed immigrations would be distributed in proportion to the number of years that each type of social unit was observed. We used a $\chi^{2}$ test to compare the expected versus actual number of immigrations.

\section{Difference between group of origin and destination}

In a subset of the secondary transfer cases, both the group of origin and the destination group were known. With this more precise dataset, we tested whether females transfer to smaller/ larger groups and to males earlier/later in their tenure. We used random intercept mixed models and each model examined one of the variables for potential influences upon secondary dispersal. For each variable (group size, elapsed tenure, and remaining tenure), the response was the difference between the group of origin and the group of destination. As an example, if a female leaves a group with 10 individuals for a group with 6 individuals, the difference between origin and destination will be -4 . This method allowed us to include the random effect of the identity of the female, identity of the group of origin, and identity of the group of destination. We then bootstrapped the results to get confidence intervals. We considered that the effect was "significant" when the $97.5 \%$ confidence limits did not overlap with zero.

\section{Results}

\section{Natal dispersal}

All 25 natal females observed since birth transferred from their natal groups, 56\% transferred voluntarily, 29\% transferred involuntarily, and in $24 \%$ of the natal transfers, the females were not observed again so they either died or dispersed to an unknown group (Table 2). In all fourteen known cases of voluntary natal transfer, the female was in a group with her putative father, which is consistent with the hypothesis that natal dispersal is driven by inbreeding avoidance. The average age ( \pm standard deviation) of natal females during those voluntary transfers was $9.1 \pm 1.0$ years (range $=7.8-$ $10.5, N=14)$. Of these fourteen females, six were subsequently observed with an infant of which $50 \%$ reproduced in the first group they transferred to while $50 \%$ transferred again, seven females were too young to breed, and one was transferred again to an unknown group or died. Natal transfers occur around 3 years prior to their first birth.
The average age of natal females making involuntary transfers was $4.8 \pm 0.8$ years (range $=4.0-6.0, N=5$ ). Of these five, two transferred together with their mother (at ages 4.8 and 5) and three transferred alone (at ages 4, 4.4, and 6). None of the females gave birth in their new group, and all of them had at least one voluntary transfer before reaching age 12 . Natal females transferring involuntarily were more likely to transfer to a group with fewer females $(t=-2.754$, df $=11.539, p=$ 0.018 , mean involuntary $=1.4$, mean voluntary $=4.4)$, but not to a smaller group $(t=-1.35, \mathrm{df}=9.25, p=0.209)$ than females transferring voluntarily. These secondary transfers illustrate that voluntary dispersal by nulliparous females may be unconditional and females may avoid breeding with a male they knew as adult during maturation.

\section{Secondary dispersal}

Females transferred on average one time every 4.5 years $(0.22$ transfers per female per year: 285 secondary transfers in 1270 female-years), although females have been recorded as transferring up to twelve times and breeding in up to four different groups. There is extreme variation in the time females spend in a particular group, ranging from a few weeks and up to 20 years for females who never transferred during the study period. The number of transfers significantly increases with time a female was observed in the population (Pearson's $r=$ $0.396, t=5.191$, df $=145, p<0.001$ ) (Fig. 2). Secondary involuntary transfers after group disintegration account for $17 \%$ ( $N=27$, during 11 group disintegrations) of all secondary transfers $(N=163)$. Of the 27 females that experienced group disintegrations, $15(56 \%)$ had unweaned infants of which 11 (73\%) disappeared (age range of infants $0.1-3.5$ years),

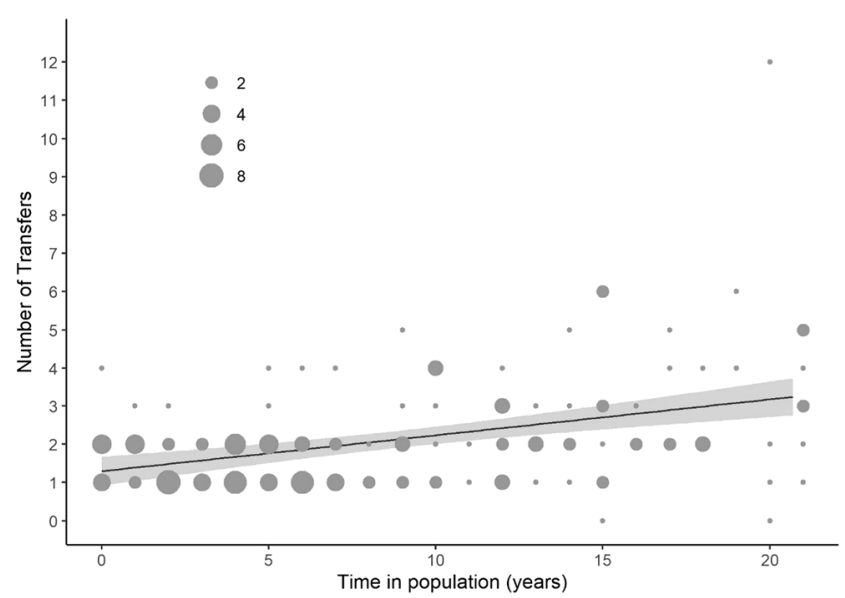

Fig. 2 Female time spend in the population against a number of transfers $(N=147)$. Each dot represents a number of transfers by one or more females (depending on the dot size) that occurred during the 1-year time period. The straight line represents the linear regression of the number of transfers against time in the population. The gray area represents the $95 \%$ confidence interval 
confirmed by the absence of the infants in the groups the females joined. We can assume that these infants died, most likely due to infanticide (Breuer et al. 2010; Robbins et al. 2013; Manguette et al. 2019). The rare cases of unweaned offspring that survived a disintegration event $(N=4)$ were either offspring that were close to weaning age or that transferred with their mother to an old solitary silverback or to a non-breeding group. In such groups, often containing only immature males with or without an older silverback, infanticide is not likely.

\section{Emigration and immigration rates}

We observed 101 cases of voluntary secondary dispersal, 62 cases in which the female disappeared, and 202 cases in which the female stayed and conceived in her current group (Table 2). The emigration rate is $33 \%$ if we assume that all of the disappearances were deaths (101/303), and $45 \%$ if we assume that they were dispersal (163/365). The actual transfer probability is likely in between the two proposed values. A total of 178 immigrations by females occurred during the 566 unit-years observed (groups and solitary males), resulting in an average rate of one immigration into a group or to a solitary male every 3 years (0.31 immigrations per unit-year).

\section{Effect of social unit type}

The immigration rate to solitary males was on average one immigration every 6 years to a solitary male $(0.16$ immigrations per unit-year: 37 immigrations during 225 unit-years of solitary males), which is significantly lower than the rate to established groups of one immigration every 2 years $(0.41$ immigrations per unit-year: 141 immigrations during 340 unit-years of groups) (chi-square $=26.8, \mathrm{df}=1, p<0.001$ ).

\section{Effect of group size}

Females were significantly more likely to emigrate from larger groups when females that disappeared were included (Fig. 3a, model 1 in Tables 3, 4). However, female transfer decisions were not significantly related to the size of the group if those females that disappeared were excluded (S2: Fig. S2a, model 1 in Tables S1, S2). The difference in these two tests may be due to enhanced statistical power from a larger dataset when disappearances were included (365 versus 303 cases). Immigration rates were significantly negatively correlated with group size (Fig. 4a, Table S5), with females more likely joining smaller groups than larger ones. When testing the difference between the group of origin and the group of destination, we found that females transferred significantly more to groups that were smaller than their previous groups; the groups of destination contained an average of four fewer weaned individuals than the origin groups (Fig. 5a, Table S6). Overall, the three different methods show similar results of females transferring to smaller groups.

\section{Effect of tenure duration}

The female emigration rate was positively correlated with the elapsed male tenure (Fig. 3b, model 2 in Tables 3, 4) and negatively correlated with the remaining male tenure (Fig. $3 \mathrm{c}$, model 3 in Tables 3, 4). Five years after a male tenure started, emigrations accounted for $18 \%$ of decisions to stay or leave and increased to $75 \%$ of decisions 15 years into the male tenure (Fig. 3b). When looking at the remaining tenure, we found that emigrations accounted for $0 \%$ of decisions to stay or leave 15 years prior to the end of a male's tenure and increased from $35 \% 5$ years before the tenure ended to $80 \%$ 1 year before the end (Fig. 3c). These patterns were similar when we excluded the individuals that disappeared (See S2: Fig. S2b, c, models 2, 3 in Tables S1, S2).

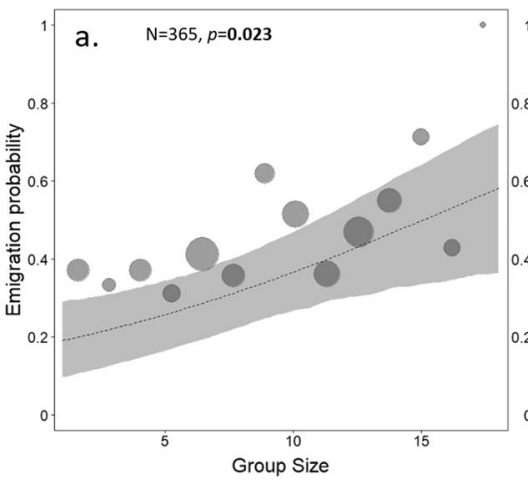

Fig. 3 a-c Emigration rate as a function of group size (a) and tenure duration separated into elapsed tenure $(\mathbf{b})$ and remaining tenure $(\mathbf{c})$. The area of the circle depicts the sample size. The dashed line shows the fitted

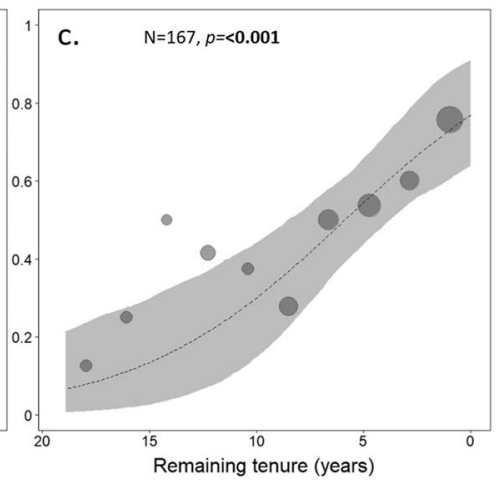

model and the gray area the $95 \%$ confidence interval for the prediction. Model results are presented in Tables 3 and 4 
Table 4 Emigration rates. Statistical details of generalized linear mixed models testing the effects of male competitive ability, feeding competition, and the death of a previous offspring on female transfer probability using a large dataset including disappearances. $p$ values considered significant $(p<0.05)$ are in italics

\begin{tabular}{llllll}
\hline Model & Fixed effects & Estimate & Standard error & $z$ & $p$ \\
\hline $1^{\text {a }}$ & Intercept & -0.652 & 0.239 & -2.730 & - \\
& Group size & 0.421 & 0.165 & 2.547 & $0.011^{b}$ \\
& Group size squared & 0.009 & 0.120 & 0.072 & 0.942 \\
& Female age & 0.247 & 0.130 & 1.908 & 0.056 \\
& Female age squared & 0.585 & 0.126 & 4.623 & $<0.001$ \\
& Intercept & -0.892 & 0.400 & -2.230 & - \\
& Elapsed tenure & 0.998 & 0.291 & 3.434 & $<0.001$ \\
& Group size & 0.395 & 0.320 & 1.237 & 0.216 \\
& Group size squared & 0.208 & 0.193 & 1.074 & 0.283 \\
& Female age & 0.331 & 0.227 & 1.458 & 0.145 \\
& Female age squared & 0.555 & 0.199 & 2.790 & 0.005 \\
& Intercept & -1.004 & 0.353 & -2.845 & - \\
& Remaining tenure & -1.389 & 0.323 & -4.298 & $<0.001$ \\
& Group size & 0.477 & 0.253 & 1.885 & 0.059 \\
& Group size squared & 0.242 & 0.233 & 1.042 & 0.297 \\
& Female age & -0.139 & 0.243 & -0.575 & 0.566 \\
& Female age squared & 0.763 & 0.198 & 3.851 & 0.001 \\
& Intercept & 0.441 & 0.317 & 1.394 & 0.163 \\
Survival of previous offspring & 0.806 & 0.455 & 1.773 & 0.076 \\
\hline
\end{tabular}

${ }^{\text {a }}$ A similar model using a smaller but more precise dataset with only transfers to known groups revealed insignificant results for the variable group size (See SI2)

${ }^{\mathrm{b}}$ Reduced model without group size squared shows similar results for the variable group size
The immigration rate was negatively correlated with the elapsed tenure (Fig. 4b) and positively correlated with the remaining tenure (Fig. 4c). The elapsed tenure model showed 1.39 immigrations per group-year for silverbacks early in their tenure (first $0-5$ years), which is four times higher than the rate of 0.35 immigrations per group-year in groups with males $>$ 12 years into their tenure. The remaining tenure model showed even a higher difference with 1.47 immigration per group-year in groups with males more than 12 years away from the end of their tenure, which is eight times higher than the rate of 0.18 immigrations per group-year during the last 5 years of the tenure (Table S5).

When comparing the group of destination with the group of origin, we found a trend for a negative effect for the elapsed

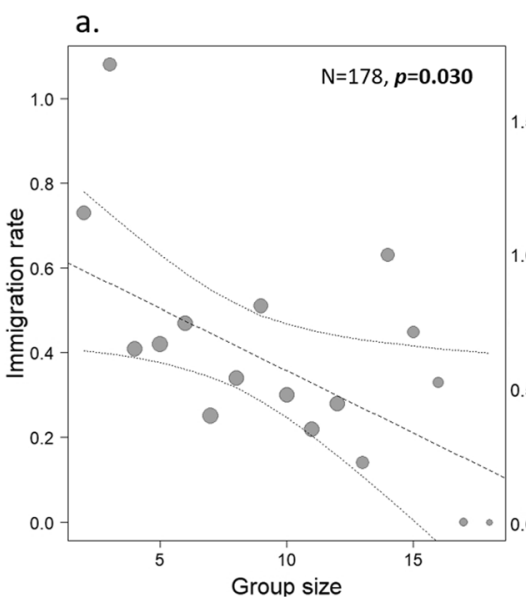

b.
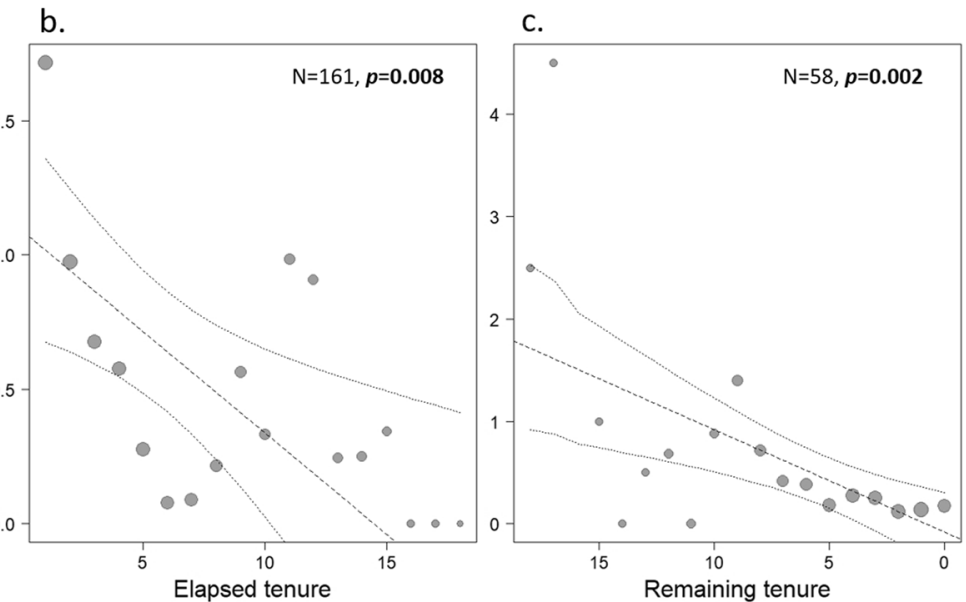

Fig. 4 a-c Immigration rate as a function of group size (a) and tenure duration separated into elapsed tenure (b) and remaining tenure (c). The area of the circle depicts the sample size. The dashed lines show the fitted model and the $95 \%$ confidence interval for the prediction. Statistical details of the linear model in Table S5 

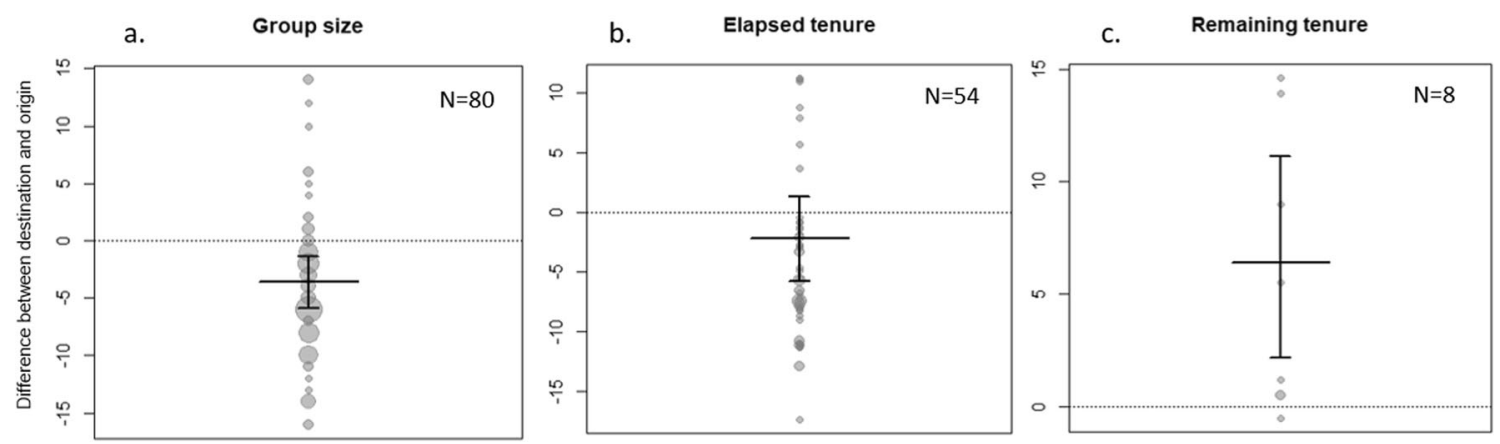

Fig. 5 a-c Difference between destination and origin group. Random intercept models for each separate variable of group size, elapsed tenure, and remaining tenure. The area of the circle depicts the sample

tenure with females transferring on average to males that were 2 years earlier in their tenure compared to their previous male (Fig. 5b, Table S6). When testing the remaining tenure, we found a significant effect of females transferring to males that were on average 6 years further away from reaching the end of their tenure compared with that of their previous silverback (Fig. 5c, Table S6).

\section{Effect of infant death}

The death of an infant had a potential influence on the probability that a female would transfer (statistical trend; model 4 in Tables 3,4). After having raised an infant to weaning age $(N=55)$, females conceived in the same group in $76 \%$ of the cases and transferred in $24 \%$. After the death of an offspring $(N=58)$, females were also more likely to stay in the same group $(62 \%)$ but left more often than after a surviving offspring (38\%).

\section{Discussion}

Female western lowland gorillas seem to have unconditional natal dispersal, which further supports the inbreeding avoidance hypothesis. Secondary emigration rates increased in response to increasing group size and male tenure duration (Table 1). The rate of female immigration decreased as both group size and male tenure duration increased. These results suggest that secondary dispersal is influenced by a combined pressure of reducing group size, which may reflect lower intra-group feeding competition and/or deflecting attention from outsider males or predators, and residing with males having high competitive ability. The importance of smaller group size for females runs counter to the male interest of having a high number of females highlighting an intersexual conflict found in gorillas. size. The results were considered significant when the $97.5 \%$ confidence limits did not overlap zero. Statistical details in Table S6

\section{Unconditional natal dispersal}

All female western lowland gorillas transfer before reaching maturity even when they are in a group with a silverback who is not their father (e.g., in a group they joined involuntarily after their group disintegrated) and therefore voluntary dispersal by nulliparous females is unconditional. In species having an adult male tenure longer than the female's average age at reproduction, it is expected that females leave a group with a putative father to avoid the costs of inbreeding (CluttonBrock and Lukas 2012). However, it is not clear why females would leave a male that is not their father unless they have enough time before the first conception to find a better male to transfer to or females are socially inhibited from breeding with males who were adults during their maturation (Watts 1990). Non-dispersing natal mountain gorilla females follow this prediction as in all cases of reproduction in a multimale group, the females bred with males who were substantially younger than the dominant male (Vigilant et al. 2015). Mating avoidance with familiar paternal relatives has also been shown in Barbary macaques (Kuester et al. 1994), savannah baboons (Alberts 1999), northern muriquis (Strier et al. 2011), and capuchin monkeys (Muniz et al. 2006). This strategy of unconditional dispersal may be advantageous if females cannot assess relatedness to the silverback of their group especially if the cost of inbreeding is much greater than the cost of dispersal. It is possible that species with high paternity certainty, such as western lowland gorillas living in one-male groups, may not be able to discern kin as well as species that have evolved in multimale groups.

\section{Female preference for smaller groups}

Gorillas are expected to have low within-group feeding competition and previous research has resulted in equivocal results for whether feeding competition has a negative effect on female reproductive success or dispersal decisions (Robbins and Robbins 2018). We found the strongest support to date for group size influencing female dispersal decisions in gorillas. 
However, these results depend partly on whether females that disappeared (unknown if they died or dispersed) are included in the models or not. Females were more likely to emigrate from larger groups and immigrate into small groups, which were on average four individuals smaller than their current group, suggesting within-group feeding competition may be occurring (Stokes 2004; Lodwick 2015). Previous studies did not find a negative relationship between reproductive success and group size, which is not consistent with increased levels of within-group feeding competition in both lowland and mountain gorillas (Robbins et al. 2007; Manguette et al. 2019), but the ability of females to disperse before experiencing any effects of within-group feeding competition may therefore prevent them from suffering reduced fitness (Dias and Strier 2003). This contrasts with female philopatric species which often suffer high reproductive costs of feeding competition in larger groups (e.g., long-tailed macaques, van Noordwijk and van Schaik 1999; yellow baboons, Packer et al. 2000; Phayre's leaf monkey, Borries et al. 2008).

Larger gorilla groups with more females could also attract more competitors which may be another argument explaining females' choice for smaller groups, even in the absence of group take-overs. There is strong evidence that groups are more likely to be targeted for take-overs once female group size becomes larger than optimal (lions: Pusey and Packer 1994; colobus monkeys: Teichroeb et al. 2012). Because female western gorillas only transfer during intergroup encounters, their transfer decisions may therefore also be based on which groups they encounter. Silverbacks leading groups with many reproductive females and/or young infants may try to avoid encounters to reduce the risk of infanticide and their females dispersing. In contrast, young silverbacks with few females in their groups or solitary males may be more motivated to seek out encounters to acquire females (Sicotte 1993). If this is true, then smaller groups should have higher rates of encounters (younger silverbacks and solitary males) and lead to more transfers into them. Furthermore, males use sexual coercion as a means to prevent female transfer, primarily by herding them away from the opposing group and/or exhibiting higher rates of aggression towards those females (Breuer et al. 2016). Females in larger groups at Mbeli Bai received less aggression from the silverbacks than those in smaller groups (Breuer et al. 2016), suggesting that it may be easier to transfer away from groups with more females. Females may also choose smaller groups to reduce harassment by resident females which may be especially true for very young females after an involuntary natal dispersal (Watts 1991).

\section{Female preference for males earlier in their tenure}

Females were more likely to join males earlier in their tenures thus males that are younger and potentially stronger. We found females dispersing away from males nearing the end of their tenure (likely aging silverbacks). Male competitive ability therefore seems to be a very important factor influencing female transfer decisions, which is consistent with the idea that females disperse for a better mate who is a better protector (Sicotte 2001). Similar results have been found for another population of western lowland gorillas (Baudouin et al. 2019) and other species including humans (Marsh 1979; Starin 1994; Sterck et al. 1997; Marlowe 2005; Robbins et al. 2009a; Teichroeb et al. 2009). In Thomas langurs, females move from groups with older, long tenure males to groups with younger adult males, resulting in females experiencing fewer potentially infanticidal attacks from extra-group males after transferring (Sterck et al. 1997, 2005). In the Hadza, better hunters have greater reproductive success and younger wives with greater reproductive value (Marlowe 2005; Apicella 2014). Female western lowland gorillas suffer higher infant mortality at the end of a male's tenure (Manguette et al. 2019). Therefore, leaving a silverback before he reaches the end of his tenure and potentially loses competitive ability or dies seems to be an advantageous strategy to prevent this loss. Seeking males with a better ability to provide protection is also suggested by our observations that transfer rates are slightly higher after the death of an infant, similar to mountain gorillas (Harcourt et al. 1976; Robbins et al. 2009b). The low percentage of female involuntary transfers $(17 \%)$ is another indication that females typically leave before the death of the silverback. Females may be able to determine that a male is losing strength by using the age of the male, the intensity or duration of their threat displays, or their inability to protect their infant (i.e., following infanticide by extra-group males or predation events).

Low immigration rates to solitary males compared with that to group silverbacks may indicate that solitary silverbacks were possibly of lower quality (e.g., less reproductive and protective value) because they were either too inexperienced to form their own breeding group, old postreproductive silverbacks, or lower quality male. At Mbeli, silverbacks who never reproduced $(N=2)$ and postreproductive silverbacks $(N=4)$ accounted for $14 \%(33.5$ out of 225.1) of all solitary silverback years indicating that most available solitary males may be too young to form their own breeding groups. Young adult males may have reduced access to mates because of a reduced capacity to protect and monopolize females (Clutton-Brock and McAuliffe 2009). For example, female orangutans avoid mating with young males that are unable to protect them against rivals (Fox 2002) and female elephant seals give calls that attract dominant males if they are courted by younger males (Cox and Le Boeuf 1977). If females use the group composition to evaluate a silverback's strength, as hypothesized by Baudouin et al. (2019), it may be difficult for a solitary male to initially attract a female and recruitment of additional females may be faster once the first female has joined. 


\section{Comparison with other gorilla populations}

The emigration rate (proportion of dispersal versus conceiving events) of 33-44\% is more than double the $13 \%$ rate found for mountain gorillas, although only slightly higher than the $32 \%$ emigration rate found when only one-male mountain gorilla groups are considered (Robbins et al. 2009c). Multimale groups are more common in mountain gorillas than in western gorillas and are believed to be a key counterstrategy to infanticide (Robbins and Robbins 2018). The lack of multimale groups in western lowland gorillas may lead to higher female dispersal rates (both voluntary and involuntary) as females have less choice of mates within the group and the silverback is not replaced by a subordinate after his death (as in the case of mountain gorillas) leading to group disintegration and female transfer in western lowland gorillas. The difference in the emigration rate is consistent with the fact that females are less likely to leave multimale groups than one-male groups due to the lower infanticide risk in multimale groups (Robbins et al. $2009 \mathrm{c}$ ). The immigration rate of 0.314 immigration per groupyear in this population is similar to both the female transfer rate reported in another population of western lowland gorilla at Loango in Gabon, of 0.26-0.48 female transfer per groupyear (Hagemann et al. 2018) and the 0.27 immigrations per group-year for mountain gorillas in one-male groups (Robbins et al. 2009c). The higher female dispersal rate in western lowland gorillas, which appears to be due to the occurrence of multimale groups in mountain gorillas, may have implications for the differences observed between gorilla species such as lower co-residence with familiar individuals including kin (Watts 2003; Bradley et al. 2007); however, that remains speculative in the absence of genetic data.

While the higher dispersal rate observed in female western lowland gorillas may lead to the low association with kin compared with that in mountain gorillas, western gorilla females have been shown to share relatedness with at least one other female in their group suggesting that dispersal does not prevent certain female kin associations (Bradley et al. 2007; Arandjelovic et al. 2014). The high transfer rate and the fact that the maximum group duration is linked to the duration of a silverback's life may lead to western gorillas having shorter group duration, average lower female co-residency time, and less incentive to form strong bonds between individuals than mountain gorillas.

Female western lowland gorillas may face more constraints on their group size than mountain gorillas due to more spatially and temporarily clumped fruit in their diet and lower availability of terrestrial herbaceous vegetation (Robbins and Robbins 2018). Western gorillas have longer travel distances and less cohesive groups (Cipolletta 2004; Doran-Sheehy et al. 2004), leading to greater group spread while feeding making it difficult for a single silverback to protect large groups from predation or infanticidal males and therefore constrain female reproductive success at larger group sizes (Tutin 1996; Doran and McNeilage 2001; Salmi and DoranSheehy 2014).

\section{Conclusion}

Female secondary dispersal is very rare in primates but is common in gorillas. Our results suggest that both group size and male competitive ability play a role, although it is difficult to disentangle the effects of each factor. If several females are attracted to the same male, the female interest in silverbacks early in their tenure may lead to higher mating competition among females (Doran-Sheehy et al. 2009) and higher withingroup feeding competition or reduced attraction by outsider males or predators (Harcourt and Stewart 2007). Attractive males very early in their tenure also tend to have smaller groups (Parnell 2002). Therefore, transfer decisions likely are made based on the sum of many factors, with the ultimate aim of maximizing reproductive success (Manguette et al. 2019).

In western lowland gorillas, females suffer sexual coercion by males (Breuer et al. 2016) but the ability to transfer between groups gives females some intersexual power not present in philopatric species (Lewis 2018). Indeed, female dispersal may explain the absence of take-overs in western lowland gorillas. If it was beneficial for females to stay, a takeover male would be guaranteed to keep all the females; however, if residency is not necessarily beneficial to females, the male efforts would be wasted if females abandoned the new silverback as soon as he evicted the resident silverback (Harcourt and Stewart 2007). However, in many female philopatric species, females have developed other counterstrategies to sexual coercion after male take-over such as pregnancy interruption (e.g., baboons, Roberts et al. 2012), infant abandonment (e.g., colobine monkeys, Sicotte et al. 2007), or acceleration of weaning (e.g., vervet monkeys, Fairbanks and McGuire 1987), all strategies which may have stronger deleterious effects on reproductive success than a "planned" secondary dispersal before the death of the silverback.

The high rate of female secondary dispersal in western gorillas coincides with groups being relatively ephemeral because they only exist as long as the silverback has females and/or is alive. This contrasts with female philopatric species and species living in multimale groups that exist for many generations and where females rely on within-group kinship and the ability to form and maintain social bonds. Such longlasting groups also may be found in multimale species with female dispersal and male philopatry such as chimpanzees (Langergraber et al. 2009; Mitani 2009). It is possible that the high degree of male-male competition in western lowland gorillas not only leads to extreme sexual dimorphism but also influences the formation of this relatively rare social system. 
Acknowledgments For permission to conduct field research in the Nouabalé-Ndoki National Park, we thank the Ministry of Sustainable Development, Forest Economy and the Ministry of Scientific Research of the Republic of Congo. We thank the Nouabalé-Ndoki Foundation and the Wildlife Conservation Society-Congo Program for the administrative and logistical support. We are grateful to Claudia Olejniczak, Kelly Greenway, and Jana Robeyst and the numerous research assistants for their help with the continuous monitoring of the clearing with a special mention to Vidrige Kandza, Franck Barrel Mavinga, and Mireille BreuerNdoundou Hockemba. We thank Laura Hagemann, Julia Metsio Sienne, and Robin Morrison for the revisions of the previous versions of the manuscript, Roger Mundry for statistical advice, and Maria van Noordwijk, Lucie Debeffe and one anonymous reviewer for their comments on this manuscript. We are also grateful to the donors of the Mbeli Bai Study, especially Columbus Zoo and Aquarium, Cincinnati Zoo and Botanical Garden, Cologne Zoo, Disney Worldwide Conservation Fund, Dublin Zoo, Sea World and Bush Gardens Conservation Fund, Toronto Zoo, Wildlife Conservation Society, and Woodland Park Zoo.

Authors' contributions MLM and MMR designed the study. MLM and AMR analyzed the data. MLM, MMR, and AMR wrote the manuscript. MLM, TB, EJS, and RJP collected the data. TB, EJS, and RJP commented on the manuscript.

Funding information Open access funding provided by Projekt DEAL. Open access funding provided by the Max Planck Society. MLM received a research grant from the German Academic Exchange Program (DAAD) and a stipend from the Max Planck Institute for Evolutionary Anthropology.

Data availability The data used for this study are available from the corresponding author on request.

\section{Compliance with ethical standards}

\section{Conflict of interest None.}

Ethical approval For this study, gorillas were observed in their natural habitat. Our observations were made from a 9-m-high platform and animals were mostly unaware of researchers' presence; we therefore believe that our study had very little disturbance to the animals or the ecosystem. All study procedures complied with the Comite d'Ethique de la Recherche en Sciences de la Santé in Brazzaville, Republique of Congo, the ethical standards of the Max Planck Institute for Evolutionary Anthropology, and the primatology department's ethical guidelines for non-invasive research.

Open Access This article is licensed under a Creative Commons Attribution 4.0 International License, which permits use, sharing, adaptation, distribution and reproduction in any medium or format, as long as you give appropriate credit to the original author(s) and the source, provide a link to the Creative Commons licence, and indicate if changes were made. The images or other third party material in this article are included in the article's Creative Commons licence, unless indicated otherwise in a credit line to the material. If material is not included in the article's Creative Commons licence and your intended use is not permitted by statutory regulation or exceeds the permitted use, you will need to obtain permission directly from the copyright holder. To view a copy of this licence, visit http://creativecommons.org/licenses/by/4.0/.

\section{References}

Alberts SC (1999) Paternal kin discrimination in wild baboons. Proc R Soc Lond B 266:1501-1506

Alberts SC (2012) Magnitude and sources of variation in male reproductive performance. In: Mitani JC, Call J, Kappeler PM, Palombit RA, Silk JB (eds) The evolution of primate societies. University Chicago Press, Chicago, pp 412-431

Amos W, Wilmer JW, Kokko H (2001) Do female grey seals select genetically diverse mates? Anim Behav 62:157-164

Apicella CL (2014) Upper-body strength predicts hunting reputation and reproductive success in Hadza hunter-gatherers. Evol Hum Behav 35:508-518

Arandjelovic M, Head JS, Boesch C, Robbins MM, Vigilant L (2014) Genetic inference of group dynamics and female kin structure in a western lowland gorilla population (Gorilla gorilla gorilla). Prim Biol 1:29-38

Bayen RH (2008) Analyzing linguistic data: a practical introduction to statistics using R. Cambridge University Press, Cambridge

Baudouin A, Gatti S, Levréro F, Genton C, Cristescu RH, Billy V, Motsch P, Pierre J-S, Le Gouar P, Ménard N (2019) Disease avoidance, and breeding group age and size condition the dispersal patterns of western lowland gorilla females. Ecology 100:e02786

Bonte D, Van Dyck H, Bullock JM, Coulon A, Delgado M, Gibbs M, Lehouck V, Matthysen E, Mustin K, Saastamoinen M (2012) Costs of dispersal. Biol Rev 87:290-312

Borries C, Larney E, Lu A, Ossi K, Koenig A (2008) Costs of group size: lower developmental and reproductive rates in larger groups of leaf monkeys. Behav Ecol 19:1186-1191

Bowler DE, Benton TG (2005) Causes and consequences of animal dispersal strategies: relating individual behaviour to spatial dynamics. Biol Rev 80:205-225

Bradley BJ, Doran-Sheehy DM, Vigilant L (2007) Potential for female kin associations in wild western gorillas despite female dispersal. Proc R Soc Lond B 274:2179-2185

Breuer T, Hockemba MB-N, Olejniczak C, Parnell RJ, Stokes EJ (2009) Physical maturation, life-history classes and age estimates of freeranging western gorillas - insights from Mbeli Bai, Republic of Congo. Am J Primatol 71:106-119

Breuer T, Robbins A, Olejniczak C, Parnell RJ, Stokes EJ, Robbins MM (2010) Variance in the male reproductive success of western gorillas: acquiring females is just the beginning. Behav Ecol Sociobiol 64:515-528

Breuer T, Robbins AM, Robbins MM (2016) Sexual coercion and courtship by male western gorillas. Primates 57:29-38

Cipolletta C (2004) Effects of group dynamics and diet on the ranging patterns of a western gorilla group (Gorilla gorilla gorilla) at Bai Hokou, Central African Republic. Am J Primatol 64:193-205

Clobert J, Baguette M, Benton TG, Bullock JM, Ducatez S (2012) Dispersal ecology and evolution. Oxford University Press, Oxford

Clobert J, Le Galliard J-F, Cote J, Meylan S, Massot M (2009) Informed dispersal, heterogeneity in animal dispersal syndromes and the dynamics of spatially structured populations. Ecol Lett 12:197-209

Clutton-Brock TH, Lukas D (2012) The evolution of social philopatry and dispersal in female mammals. Mol Ecol 21:472-492

Clutton-Brock TH, McAuliffe K (2009) Female mate choice in mammals. Q Rev Biol 84:3-27

Cox CR, Le Boeuf BJ (1977) Female incitation of male competition: a mechanism in sexual selection. Am Nat 111:317-335

Debeffe L, Richard E, Medill SA, Weisgerber JN, McLoughlin PD (2015) Costs of social dispersal in a polygynous mammal. Behav Ecol 26:1476-1485

Dias LG, Strier KB (2003) Effects of group size on ranging patterns in Brachyteles arachnoides hypoxanthus. Int J Primatol 24:209-221 
Dobson AJ, Barnett A (2008) An introduction to generalized linear models. CRC press, Boca Raton

Doran DM, McNeilage A (2001) Subspecific variation in gorilla behavior: the influence of ecological and social factors. In: Robbins MM, Sicotte P, Stewart KJ (eds) Mountain gorillas: three decades of research at Karisoke. Cambridge University Press, Cambridge, pp 123-150

Doran-Sheehy DM, Fernández D, Borries C (2009) The strategic use of sex in wild female western gorillas. Am J Primatol 71:1011-1020

Doran-Sheehy DM, Greer D, Mongo P, Schwindt D (2004) Impact of ecological and social factors on ranging in western gorillas. Am J Primatol 64:207-222

Fairbanks L, McGuire M (1987) Mother-infant relationships in vervet monkeys: response to new adult males. Int J Primatol 8:351-366

Field A (2005) Regression. Discovering statistics using SPSS. Sage publications, London

Forstmeier W, Schielzeth H (2011) Cryptic multiple hypotheses testing in linear models: overestimated effect sizes and the winner's curse. Behav Ecol Sociobiol 65:47-55

Fox EA (2002) Female tactics to reduce sexual harassment in the Sumatran orangutan (Pongo pygmaeus abelii). Behav Ecol Sociobiol 52:93-101

Gatti S, Levréro F, Ménard N, Gautier-Hion A (2004) Population and group structure of western lowland gorillas (Gorilla gorilla gorilla) at Lokoue, Republic of Congo. Am J Primatol 63:111-123

Grueter CC, Robbins AM, Abavandimwe D, Vecellio V, Ndagijimana F, Ortmann S, Stoinski TS, Robbins MM (2018) Quadratic relationships between group size and foraging efficiency in a herbivorous primate. Sci Rep 8:16718

Hagemann L, Boesch C, Robbins MM, Arandjelovic M, Deschner T, Lewis M, Froese G, Vigilant L (2018) Long-term group membership and dynamics in a wild western lowland gorilla population (Gorilla gorilla gorilla) inferred using non-invasive genetics. Am J Primatol 80:1-12

Harcourt AH, Stewart KJ (2007) Gorilla society: conflict, compromise, and cooperation between the sexes. Chicago University Press, Chicago

Harcourt AH, Stewart K, Fossey D (1976) Male emigration and female transfer in wild mountain gorilla. Nature 263:226-227

Hill RA, Lee PC (1998) Predation risk as an influence on group size in cercopithecoid primates: implications for social structure. J Zool 245:447-456

Ims RA, Hjermann DO (2001) Condition-dependent dispersal. In: Clobert J, Danchin E, Dhondt AA, Nichols JD (eds) Dispersal. Oxford University Press, Oxford, pp 203-2016

Isbell LA, Van Vuren D (1996) Differential costs of locational and social dispersal and their consequences for female group-living primates. Behaviour 133:1-36

Kuester J, Paul A, Arnemann J (1994) Kinship, familiarity and mating avoidance in Barbary macaques, Macaca sylvanus. Anim Behav 48: 1183-1194

Langergraber K, Mitani J, Vigilant L (2009) Kinship and social bonds in female chimpanzees (Pan troglodytes). Am J Primatol 71:840-851

Lewis RJ (2018) Female power in primates and the phenomenon of female dominance. Annu Rev Anthropol 47:533-551

Lodwick JL (2015) Links between foraging strategies, feeding competition, and female agonistic relationships in wild western gorillas (Gorilla gorilla). The Graduate School, Stony Brook University, Dissertation

Lukas D, Clutton-Brock TH (2011) Group structure, kinship, inbreeding risk and habitual female dispersal in plural-breeding mammals. J Evol Biol 24:2624-2630

Manguette ML, Robbins AM, Breuer T, Stokes EJ, Parnell RJ, Robbins MM (2019) Intersexual conflict influences female reproductive success in a female-dispersing primate. Behav Ecol Sociobiol 73:118
Markham AC, Gesquiere LR, Alberts SC, Altmann J (2015) Optimal group size in a highly social mammal. P Natl Acad Sci USA 112: 14882-14887

Marlowe FW (2005) Hunter-gatherers and human evolution. Evol Anthropol 14:54-67

Marsh CW (1979) Female transference and mate choice among Tana River red colobus. Nature 281:568-569

Mitani JC (2009) Male chimpanzees form enduring and equitable social bonds. Anim Behav 77:633-640

Muniz L, Perry S, Manson JH, Gilkenson H, Gros-Louis J, Vigilant L (2006) Father-daughter inbreeding avoidance in a wild primate population. Curr Biol 16:R156-R157

Nagy M, Heckel G, Voigt CC, Mayer F (2007) Female-biased dispersal and patrilocal kin groups in a mammal with resource-defence polygyny. Proc R Soc Lond B 274:3019-3025

Packer C, Collins DA, Eberly LE (2000) Problems with primate sex ratios. Phil Trans R Soc B 355:1627-1635

Parnell RJ (2002) Group size and structure in western lowland gorillas (Gorilla gorilla gorilla) at Mbeli Bai, Republic of Congo. Am J Primatol 56:193-206

Pusey, AE, Packer C (1994) Infanticide in lions: consequences and counterstrategies. In: Parmigiani S, vom Saal F (eds) Infanticide and parental care. Harwood Academic Publishers, Chur, pp 277-299

R Core Team (2017) R: a language and environment for statistical computing. R Foundation for Statistical Computing, Vienna, Austria http://www.R-project.org

Robbins AM, Gray M, Basabose A, Uwingeli P, Mburanumwe I, Robbins MM (2013) Impact of male infanticide on the social structure of mountain gorillas. PLoS One 8:e78256

Robbins AM, Robbins MM (2015) Dispersal patterns of females in the genus Gorilla. In: Furuichi T, Yamagiwa J, Aureli F (eds) Dispersing primate females. Springer, Berlin, pp 75-104

Robbins AM, Stoinski T, Fawcett K, Robbins MM (2009a) Leave or conceive: natal dispersal and philopatry of female mountain gorillas in the Virunga volcano region. Anim Behav 77:831-838

Robbins AM, Stoinski TS, Fawcett KA, Robbins MM (2009b) Does dispersal cause reproductive delays in female mountain gorillas? Behaviour 146:525-549

Robbins AM, Stoinski TS, Fawcett KA, Robbins MM (2009c) Socioecological influences on the dispersal of female mountain gorillas - evidence of a second folivore paradox. Behav Ecol Sociobiol 63:477-489

Robbins MM, Robbins AM (2018) Variation in the social organization of gorillas: life history and socioecological perspectives. Evol Anthropol 27:218-233

Robbins MM, Robbins AM, Gerald-Steklis N, Steklis HD (2007) Socioecological influences on the reproductive success of female mountain gorillas (Gorilla beringei beringei). Behav Ecol Sociobiol 61:919-931

Roberts EK, Lu A, Bergman TJ, Beehner JC (2012) A Bruce effect in wild Geladas. Science 335:1222-1225

Salmi R, Doran-Sheehy DM (2014) The function of loud calls (hoot series) in wild western gorillas (Gorilla gorilla): Gorilla long calls and group cohesion. Am J Phys Anthropol 155:379-391

Sicotte P (1993) Inter-group encounters and female transfer in mountain gorillas: influence of group composition on male behavior. Am J Primatol 30:21-36

Sicotte P (2001) Female mate choice in mountain gorillas. In: Robbins MM, Sicotte P, Stewart KJ (eds) Mountain gorillas: three decades of research at Karisoke. Cambridge University Press, Cambridge, pp $59-87$

Sicotte P, Teichroeb JA, Saj TL (2007) Aspects of male competition in Colobus vellerosus: preliminary data on male and female loud calling, and infant deaths after a takeover. Int J Primatol 28:627-636 
Sicotte P, Teichroeb JA, Vayro JV, Fox SA. Badescu J, Wikberg EC (2017) The influence of male takeovers on female dispersal in Colobus vellerosus. Am J Primatol 79:e22436

Starin E (1994) Philopatry and affiliation among red colobus. Behaviour 130:253-270

Steenbeek R (2000) Infanticide by males and female choice in wild Thomas's langurs. In: van Schaik CP, Janson CH (eds) Infanticide by males and its implications. Cambridge University Press, Cambridge, pp 153-177

Sterck EHM, Korstjens AH (2000) Female dispersal and infanticide avoidance in primates. In: van Schaik CP, Janson CH (eds) Infanticide by males and its implications. Cambridge University Press, Cambridge, pp 293-321

Sterck EHM, Watts DP, van Schaik CP (1997) The evolution of female social relationships in nonhuman primates. Behav Ecol Sociobiol 41:291-309

Sterck EHM, Willems EP, van Hooff JARAM, Wich SA (2005) Female dispersal, inbreeding avoidance and mate choice in Thomas langurs (Presbytis thomasi). Behaviour 142:845-868

Stokes EJ (2004) Within-group social relationships among females and adult males in wild western lowland gorillas (Gorilla gorilla gorilla). Am J Primatol 64:233-246

Stokes EJ, Parnell RJ, Olejniczak C (2003) Female dispersal and reproductive success in wild western lowland gorillas (Gorilla gorilla gorilla). Behav Ecol Sociobiol 54:329-339

Strier KB (1994) Myth of the typical primate. Am J Phys Anthropol 37: 233-271

Strier KB, Chaves PB, Mendes SL, Fagundes V, Di Fiore A (2011) Low paternity skew and the influence of maternal kin in an egalitarian, patrilocal primate. P Natl Acad Sci USA 108:18915-18919

Teichroeb JA, Wikberg EC, Badescu J, Macdonald LJ, Sicotte P (2012) Infanticide risk and male quality influence group composition for Colobus vellerosus. Behav Ecol 23:1348-1359
Teichroeb JA, Wikberg EC, Sicotte P (2009) Female dispersal patterns in six groups of ursine colobus (Colobus vellerosus): infanticide avoidance is important. Behaviour 146:551-582

Tutin CE (1996) Ranging and social structure of lowland gorillas in the Lopé reserve, Gabon. In: McGrew WC, Marchant LF, Nishida T (eds) Great ape societies. Cambridge University Press, Cambridge, pp 58-70

van Noordwijk MA, van Schaik CP (1999) The effects of dominance rank and group size on female lifetime reproductive success in wild long-tailed macaques, Macaca fascicularis. Primates 40:105-130

van Schaik CP (1989) The ecology of social relationships amongst female primates. In: Foley V (ed) Comparative socioecology. Blackwell, London, pp 195-218

Vigilant L, Roy J, Bradley BJ, Stoneking CJ, Robbins MM, Stoinski TS (2015) Reproductive competition and inbreeding avoidance in a primate species with habitual female dispersal. Behav Ecol Sociobiol 69:1163-1172

Walker KK, Walker CS, Goodall J, Pusey AE (2018) Maturation is prolonged and variable in female chimpanzees. J Hum Evol 114: $131-140$

Watts DP (1989) Infanticide in mountain gorillas: new cases and a reconsideration of the evidence. Ethology 81:1-18

Watts DP (1990) Ecology of gorillas and its relation to female transfer in mountain gorillas. Int J Primatol 11:21-45

Watts DP (1991) Harassment of immigrant female mountain gorillas by resident females. Ethology 89:135-153

Watts DP (2003) Gorilla social relationships: a comparative overview. In: Taylor AB, Goldsmith ML (eds) Gorilla biology: a multidisciplinary perspective. Cambridge University Press, Cambridge, pp 302-327

Young AJ, Carlson AA, Clutton-Brock T (2005) Trade-offs between extraterritorial prospecting and helping in a cooperative mammal. Anim Behav 70:829-837

Publisher's note Springer Nature remains neutral with regard to jurisdictional claims in published maps and institutional affiliations.

\section{Affiliations}

\section{Marie L. Manguette ${ }^{1,2}$ (D) Andrew M. Robbins ${ }^{1} \cdot$ Thomas Breuer $^{2,3} \cdot$ Emma J. Stokes $^{4} \cdot$ Richard J. Parnell $^{4}$. Martha M. Robbins ${ }^{1}$}

Andrew M. Robbins

htram@aol.com

Thomas Breuer

breuer1@gmx.de

Emma J. Stokes

estokes@wcs.org
Richard J. Parnell

parnellmayumba@yahoo.co.uk

Martha M. Robbins

robbins@eva.mpg.de
1 Department of Primatology, Max Planck Institute for Evolutionary Anthropology, Deutscher Platz 6, 04103 Leipzig, Germany

2 Mbeli Bai Study, Wildlife Conservation Society Congo Program, B.P. 14537 Brazzaville, Congo
3 World Wide Fund for Nature, Reinhardtstrasse 18, 10117 Berlin, Germany

4 Wildlife Conservation Society, Global Conservation Program, 2300 Southern Boulevard, Bronx, NY 10460, USA 